\title{
KORONER ARTER BAYPAS OPERASYONLARINDA OTOLOG VENA SAFENA MAGNA ÇIKARILMASINDA ENDOSKOPIK, TÜNEL VE STANDART YÖNTEMIN KARŞILAŞTIRILMASI
}

\author{
THE COMPARISON OF STANDARD, ENDOSCOPIC AND TUNNEL HARVESTING OF \\ AUTOLOG VENA SAPHENA MAGNA IN CORONARY ARTERY BYPASS GRAFTING \\ OPERATIONS
}

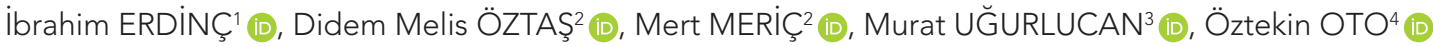 \\ 'Bozyaka Eğitim Araştırma Hastanesi, Kalp ve Damar Cerrahisi Birimi, İzmir, Türkiye \\ 2istanbul Üniversitesi, İstanbul Tıp Fakültesi, Kalp ve Damar Cerrahisi Anabilim Dalı, İstanbul, Türkiye \\ ${ }^{3}$ Medipol Mega Üniversite Hastanesi, Kalp ve Damar Cerrahisi Anabilim Dalı, İstanbul, Türkiye \\ ${ }^{4}$ Dokuz Eylül Üniversitesi Tıp Fakültesi, Kalp ve Damar Cerrahisi Anabilim Dalı, İzmir, Türkiye
} ORCID IDs of the authors: I.E. 0000-0003-1659-2859; D.M.Ö. 0000-0003-4108-6405; M.M. 0000-0001-8570-4231, M.U. 0000-0001-6643-9364;
Ö.O. 0000-0002-8595-6006

Cite this article as: Erdinc I, Oztas DM, Meric M, Ugurlucan M, Oto O. The comparison of standard, endoscopic and tunnel harvesting of autolog vena saphena magna in coronary artery bypass grafting operations. J Ist Faculty Med 2020;83(2):119-26. doi: 10.26650/IUITFD.2019.0021

\section{ÖZET}

Amaç: Otolog Vena Saphena Magna (VSM) koroner arter cerrahisinde kullanılan en yaygın baypas materyalidir. Genellikle Vena Saphena Magna standart uzun medial bacak insizyonu ile hazırlanmakta olup; insizyon hattında iyileşme problemleri sıklıkla izlenmektedir. Bu çalışmada, otolog VSM çıkarılmasında endoskopik yöntem, klasik ve tünel yöntemlerinin karşılaştırması yapılmıştır.

Gereç ve Yöntem: Koroner baypas ameliyatı olan 40 hasta randomize ve retrospektif olarak seçildi. 10 hastada endoskopik yöntem ile, 15 hastada tünel ve 15 hastada klasik yöntem ile VSM çıkarılmıştır. Çalışmada bacak insizyonu ile ilgili olarak postop hastanede kalış süresi, kullanılan antibiyoterapi, ek antibiyotik ihtiyacı, üst bacak çapı, sızıntı, hematom, açık yara bakım süresi, kültür antibiyogram, insizyon boyutu, komplikasyon yeri, maliyet, postoperatif şikayet, ortalama VSM çıkarma süresi, VSM uzunluğu, kapalı pansuman günü, elastik bandaj süresi, drenaj miktarı, postoperatif ağrı skorlaması karşılaştııılmıştır.

Bulgular: Tünel ve endoskopik yöntem grubunda çalışma sonunda klasik gruba göre, insizyon uzunluğunda, postoperatif ağrıda, major komplikasyon gelişiminde, insizyonu kapama süresinde, insizyonu kapamada kullanılan sütür materyalinde azalma saptanmıştır. Bunun yanında mükemmel bir kozmetik sonuçla

\begin{abstract}
Objective: Autologous vena saphena magna is the most common bypass material used in coronary artery surgery. It is generally prepared with a long medial leg incision, and so healing problems are often observed. In this study, we aimed to compare endoscopic, classical and tunnel techniques in saphen harvesting.
\end{abstract}

Material and Method: Fourty patients, who were selected randomly and retrospectively, were included in the study. Endoscopic saphen harvesting was performed on 10 patients, the tunnel technique was performed on 15 patients and the classical method was performed on 15 patients. Postoperative hospital stay, antibiotics, additional antibiotic requirement, upper leg size, hematoma, open care time, culture antibiogram, incision size, complication site, cost, postoperative complaints, median vena saphena magna harvesting time, vena saphena magna length, closed dressing time, elastic bandage time, drenaige amount, postoperative pain scores (Visual Analogue Scale-VAS) were all factors compared regarding saphen insicion site.

Results: In tunnel end endoscopic procedures; insicion length, postoperative pain, major complication rate, incision closure time, the sutur material reqired for closing incisions were lower than the classical technique group. Moreover, the level of pa-

İletişim kurulacak yazar/Corresponding author: ibrahimerdinc@yahoo.com

Başvuru/Submitted: 03.03.2019 • Revizyon Talebi/Revision Requested: 01.04.2019 •

Son Revizyon/Last Revision Received: 05.04.2019 • Kabul/Accepted: 06.05.2019 • Online Yayın/Published Online: 11.12 .2019

CTelif Hakkı 2020 J Ist Faculty Med - Makale metnine jmed.istanbul.edu.tr web sayfasından ulaşılabilir.

(C) Copyright 2020 by J Ist Faculty Med - Available online at jmed.istanbul.edu.tr 
hasta memnuniyeti artmış, erken dönemde mobilizasyonda rahatlık sağlanmıştır.

Sonuç: Klasik yönteme göre endoskopik teknik ve tünel yöntemi uygulanan hastalarda bacaktaki insizyon sorunlarının daha az görüldüğü ve hastanede kalış süresinin, kullanılan sütür materyali miktarı ve insizyonu kapama süresinin, insizyon uzunluğunun ve postoperatif ağrının daha az olduğu gözlenmiştir. Hastanın mobilize olma süresinin de kısaldığı saptanmıştır. Bu sonuçlara göre endoskopik ve tünel yöntemlerinin kullanımının klasik yönteme üstünlüğü göz önünde bulundurulmalıdır.

Anahtar Kelimeler: Koroner baypas, vena safena magna, minimal invaziv teknikler

\section{Giriş}

Koroner baypas operasyonlarında bir çok greft seçeneği olmasına rağmen sıklıkla Vena Safena Magna (VSM) tercih edilmektedir. Günümüzde koroner baypas operasyonlarının \%98'inde greft olarak VSM kullanılmaktadır (1, 2). Arteriyel greftlerin kullanımının artmasına rağmen VSM halen sıklıkla tercih edilen grefttir. Bu sebeple VSM çıkarılması koroner ve periferik vasküler cerrahi için rutin bir yöntemdir (3).

VSM çıkarılması günümüzde üç farklı yöntemle yapılmaktadır. Bu yöntemler: Klasik (standart) yöntem, köprüleme (tünel) yöntemi ve endoskopik yöntemdir. Endoskopik ve tünel yöntemleri minimal invaziv yöntemler olarak da tanımlanmışlardır (1, 4). Literatürde klasik yöntemle VSM çıkarılması halinde bacakta insizyon yeri komplikasyonları \%24.3 ile \%43.8 olarak belirtilmiştir (5). Şiddetli insizyon yeri komplikasyonları ise \%1-3 oranında görülmektedir (6).

Günümüzde minimal invaziv yöntemlerle travmanin azaltılması ve kozmetik memnuniyet açısından iyi sonuçlar alınmaktadır (7). Minimal invaziv VSM çıkarılması ile morbiditede belirgin bir azalma gözlenmiştir $(1,7)$. Ayrıca endotelial yapı ve fonksiyonlarda bir farklılık gözlenmemiştir (8).

Komplikasyonların azaltılmasında daha küçük cilt insizyonları ile VSM çıkarılması için geliştirilen mekanik cerrahi araçlar son yıllarda önemli araştırma konusu olmuştur (16).

Bizim çalışmamızın amacı; koroner baypas cerrahisi geçirecek hastalara retrospektif, randomize uygulanan üç farklı VSM çıkarılma yönteminin avantajlarının ve dezavantajlarının karşılaştırılmasıdır.

\section{GEREÇ VE YÖNTEM}

Koroner baypas operasyonu yapılan hastalardan randomize ve retrospektif olarak seçilen 40 hasta bu çalışmaya alınmıştır. Hastalardan $15^{\prime}$ ine standart VSM çıkarma yöntemi, 10'una endoskopik yöntem ile safen çıkarma ve tients' satisfaction was increased due to perfect cosmetic results and ease of early mobilization.

Conclusion: Comparing classical saphen harvesting techniques with endoscopic and tunnel methods, it was found that incision problems, length of hospital stay, sutur material amounts, incision closure time, incision length and postoperative pain were detected in lower numbers in endoscopic and tunnel methods. Depending on these factors, the patient's mobilization time was shortened. According to these results, the superiority of the endoscopic and tunnel methods compared to the classical method should be considered.

Keywords: Coronary bypass, vena saphena magna, minimally invasive techniques

$15^{\prime}$ ine tünel yöntemi ile safen çıkarma tekniği uygulandı. 3 grup arasında karşılaştırma yapıldı. Endoskopik yöntem grubunda 1 kadın, 9 erkek; tünel tekniği grubunda 2 kadın, 13 erkek; standart yöntemde 2 kadın, 13 erkek bulunmaktaydı. Komorbiditesi olan hastalar (diyabet, obezite) çalışmadan çıkarılmadı. Yaş ortalaması endoskopik yöntem grubunda 63.8 \pm 10.3 , tünel grubunda 59.8 \pm 6.2 , klasik grupta $62.5 \pm 7.7 \mathrm{idi}$. Tüm olgular çalışmaya alınmadan önce bilgilendirildi ve izinleri alındı.

\section{Incelenen parametreler}

Postoperatif hastanede kalış süresi, kullanılan antibiyoterapi, ek antibiyotik ihtiyacı, üst bacak çapı, sızıntı, hematom, açık bakım süresi, kültür antibiyogram, insizyon boyutu, komplikasyon yeri, maaliyet, postoperatif şikayet, ortalama VSM çıkarma süresi, VSM uzunluğu, kapaIı pansuman günü, elastik bandaj süresi, drenaj miktarı, postoperatif ağrı skorlaması (Visual Analogue Scale-VAS) incelendi.

\section{Angiografi ve operasyon endikasyonları}

Olguların tümünün anjiografik çalışmaları Dokuz Eylül Üniversitesi Tıp Fakültesi Kardiyoloji Anabilim Dalı tarafından, Sones ve Judkins teknikleri ile koroner arterler için multipl oblik ve angulated pozisyonda, sol ventrikülografi için de sağ anterior oblik pozisyonda yapıldı. Anjiografiler Cine Wiew Elmo CO. Japan cihazında Göğüs Kalp ve Damar Cerrahisi - Kardiyoloji ortak konseyinde değerlendirilip, operasyon endikasyonları ACC/AHA (American College of Cardiology/American Heart Assosiation) Guidelines göz önünde bulundurularak konuldu.

\section{Cerrahi teknik}

Tüm olgularda median sternotomi sonrası LiMA çıkarılmıştır. Aynı zamanda seçilen hastalarda, endoskopik grupta Endoskopic Harvest Tray (TTVO1, Ethicon ${ }^{\circledR}$, Endosurgery Cinncinnati, $\mathrm{OH})$, tünel grubunda Langenback retraktör, standart grupta da cerrahi materyaller kullanılarak VSM greft olarak hazırlandı. Bazı olgularda RiMA greft olarak kullanıldı. Endoskopik yöntemde standart mediastinoskopi malzemeleri olan TV monitörü, ışık kaynağı, fiberoptik kamera ve 5 mm'lik optik lens (30 derece açılı) kullanılmıştır. Koroner baypas operas- 
yonları klasik cerrahi prosedüre uygun olarak gerçekleştirilmiştir.

Bu sırada çıkarılan VSM insizyon yerleri standart yöntemde fasya, cilt altı ve cilt; tünel tekniği ve endoskopik yöntemde ise sadece cilt sütürü ile kapatılmıştır. Endoskopik teknik ve tünel yönteminde de, klasik yöntem gibi hastaların bacak insizyonları heparin nötralize edilmeden kapatılmışır. Endoskopik yöntem ve tünel tekniğinde olası kanamaları gözlemlemek amacı ile insizyonlardan içeri Haemovac ${ }^{\circledR}$ drenaj sistemi yerleştirilmiştir.

Operasyon sonrası yoğun bakım izlemine alınan hastalara, drenaj ve ACT kontrollerine göre postoperatif 4. ila 6. saatler arasında intravenöz heparin başlanmıştır ve oral alımı olana dek devam edilmiştir. Oral alım başladığında ise $150 \mathrm{mg} /$ gün salisilik asit per oral verilmiştir. Standart grupta 1 hastaya mitral ring anüloplasti ve intraaortik baIon pompası (IABP), 1 hastaya sol ventrikül anevrizmektomi, tünel metodunda 1 hastaya IABP, endoskopik grupta da kronik böbrek yetmezliği (KBY) olan 1 hastaya çalışan kalpte çiftli baypas uygulanmıştır.

\section{Postoperatif İzlem}

Postoperatif 1. günde drenaj miktarı kontrol edilerek drenajı olmayan hastaların Haemovac ${ }^{\circledR}$ drenleri çekildi. Drenajı 25 cc üstünde olan hastaların drenleri yerinde bırakılarak postoperatif 2. günde kontrol edilerek drenajı olmayan ya da $25 \mathrm{cc}$ altında olan hastaların drenleri çekildi. Postoperatif 1. günden başlayarak hastaların insizyonları, günlük pansumanları kontrol edilerek patolojik bulgular not edildi. Komplikasyon gözlenen hastalar tespit edildi. Postoperatif 1, 3 ve 7. günlerde ağrı skalaları VAS (Visual Analogue Scale) ile not edildi. VAS seçilmesinin nedeni; düz bir hat boyunca ağrının şiddetinin belirlenmesine dayanır. Bu hatta $10 \mathrm{~cm}$ uzunlukta başlangıç noktasında ağıı olmayan 0 (sıfır) noktası sonda ise dayanılmaz ağıı olan 10 sayı noktası vardır. Hastaya açıklama yapıldıktan sonra, ağrısının şiddetini 0-10 puan arasında bir yere yer- leştirmesi söylenir. Bu yöntemin avantajı 5 yaşın üzerinde yapılabilmesi ve zamanla aynı ölçütlerle tekrar ölçülebilir olmasıdır $(9,10)$.

Komplikasyon gelişen hastalarda yara yeri bakımı, sık pansuman ve açık olan yara yerinden kültür antibiyogram yapılması planlandı. Taburculuktan sonraki ilk kontrollerinde hastaların VSM insizyonlarında komplikasyon olup olmadığı kontrol edildi ve ağrı skalası tekrar değerlendirildi.

\section{İstatistik}

İstatistiksel çalışmalar SPSS 8.0 programı kullanılarak yapıldı. Kategorik değerlerde gruplar arasındaki farklılık için Pearson Chi-Square testi kullanıldı. Gruplar arasındaki ölçülebilen değerlerde independent t-testi ile Mann-Whitney $\mathrm{U}$ testi kullanıldı. $\mathrm{P}<0.05$ değerleri istatistiksel olarak anlamlı kabul edildi.

\section{BULGULAR}

\section{Başlangıç özellikleri}

Endoskopik yöntem grubunda 1 kadın, 9 erkek; tünel tekniği grubunda 2 kadın, 13 erkek; standart yöntemde 2 kadın, 13 erkek bulunmaktaydı. Komorbiditesi olan hastalar (diyabet, obezite) çalışmadan çıkarılmadı. Yaş ortalaması endoskopik yöntem grubunda 63.8 \pm 10.3 , tünel grubunda $59.8 \pm 6.2$, klasik grupta $62.5 \pm 7.7$ idi. Klasik yöntem uygulanan hastaların 4 'ünde, tünel tekniği uygulanan hastaların 3'ünde ve endoskopik yöntem uygulanan hastaların 2'sinde Diyabetes Mellitus mevcuttu. Klasik yöntem grubunda 1 hastada diz üstü, 14 hastada hem diz üstü hem diz altı safen çıkarıldı. Tünel tekniğinde 3 hastadan diz üstü, 12 hastadan hem diz üstü hem diz altı safen çıkarıldı. Endoskopik yöntem grubunda 2 hastadan diz üstü, 2 hastadan diz altı, 6 hastadan ise hem diz üstü hem diz altı safen çıkarıldı. Çalışmaya alınan olguların preoperatif özellikleri Tablo 1'de gösterilmiştir.

Tablo 1: Hastaların preoperatif genel özellikleri

\begin{tabular}{lccc}
\hline & Klasik & Tünel & Endoskopik \\
Hasta sayısı & 15 & $15(\mathrm{P}=0.177)$ & $10(\mathrm{P}=0.177)$ \\
$\begin{array}{l}\text { Ortalama yaş (yıl) } \\
\text { Cinsiyet }\end{array}$ & $64 \pm 10$ & $63 \pm 6(\mathrm{P}=0.170)$ & $60 \pm 5(\mathrm{P}=0.397)$ \\
$\quad$ Erkek & 13 & & \\
$\quad$ Kadın & 2 & $13(\mathrm{P}=0.897)$ & $9(\mathrm{P}=0.783)$ \\
Diyabetes mellitus & 4 & $3(\mathrm{P}=0.965)$ & $1(\mathrm{P}=0.789)$ \\
Çıkarılma alanı & & & $2(\mathrm{P}=0.887)$ \\
$\quad$ Diz üstü & 1 & $3(\mathrm{P}=0.520)$ & \\
$\quad$ Diz altı & 0 & 0 & $2(\mathrm{P}=0.529)$ \\
$\quad$ Diz üstü + altı & 14 & $12(\mathrm{P}=0.232)$ & $2(\mathrm{P}=0.043)$ \\
& & & $6(\mathrm{P}=0.131)$ \\
\hline
\end{tabular}


Tablo 2: Çalışma sonunda elde edilen bulgular.

\begin{tabular}{|c|c|c|c|c|}
\hline & Klasik & Tünel & Endoskopik & P Değeri \\
\hline Hastanede kalış süresi & $10 \pm 2$ & $8 \pm 2(P=0.003)$ & $7 \pm 2(P=0.002)$ & \\
\hline Maliyet & 8250000 & $3950000(P=0.000)$ & $3950000(P=0.000)$ & \\
\hline Çıkarma süresi & $48 \pm 15$ & $62 \pm 19(P=0.045)$ & $62 \pm 9(P=0.012)$ & \\
\hline Kapama süresi & $25 \pm 6$ & $9 \pm 3(P=0.001)$ & $8 \pm 1(P=0.000)$ & \\
\hline Safen boyu & $53 \pm 13$ & $47 \pm 12(P=0.074)$ & $41 \pm 12(P=0.019)$ & \\
\hline İnsizyon uzunluğu & $54 \pm 13$ & $19 \pm 6(P=0.000)$ & $13 \pm 5(P=0.000)$ & \\
\hline Ağrı 1.gün & $6 \pm 1$ & $4 \pm 0(P=0.000)$ & $3 \pm 0(P=0.000)$ & \\
\hline Ağrı 3.gün & $4 \pm 0$ & $3 \pm 0(P=0.000)$ & $2 \pm 0(P=0.000)$ & \\
\hline Ağnı 7.gün & $3 \pm 0$ & $2 \pm 0(P=0.000)$ & $0 \pm 0(P=0.000)$ & \\
\hline Ağrı kontrol & $2 \pm 0$ & $0 \pm 0(P=0.000)$ & $0 \pm 0(P=0.000)$ & \\
\hline Drenaj & $0 \pm 0$ & $37 \pm 30$ & $79 \pm 61$ & 0.062 \\
\hline Komplikasyon & 3 & $2(P=0.715)$ & $1(P=0.403)$ & \\
\hline
\end{tabular}

Olguların başlangıç özellikleri açısından istatistiki olarak anlamlı bulgu sadece endoskopik yöntem ile diz altı safen çıkarılan grupta saptanmışır, diğer özellikleri bakımından anlamlı bulguya rastlanmamıştır. Tablo 2'de çalışma sonunda elde edilen bulgular görülmektedir.

\section{VSM çıkarma, insizyonunu kapama ve total süreleri}

Olguların VSM çıkarma süreleri Şekil 1'de gösterilmiş̧ir. Klasik grupta VSM çıkarma süresi $48 \pm 15 \mathrm{dk}$., insizyonu kapama süresi $25 \pm 6 \mathrm{dk}$. ve total süre $73 \pm 12 \mathrm{dk}$. olarak saptanmıştır.

\section{Süre (Dakika)}

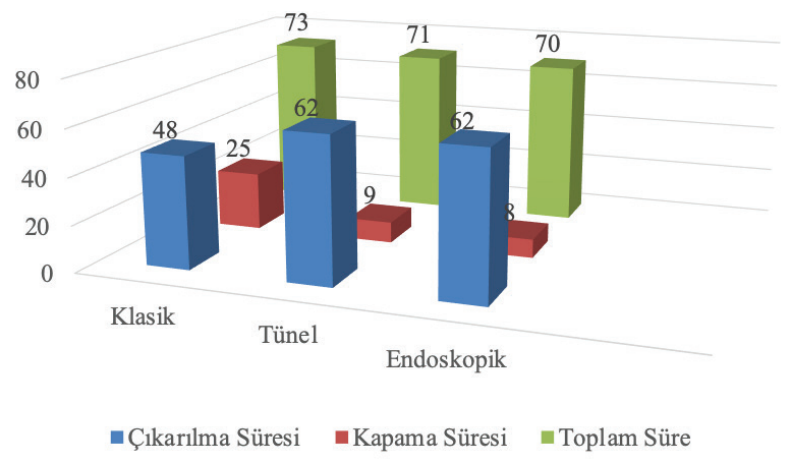

Şekil 1: Olguların intraoperatif VSM çıarma, insizyonunu kapama ve total süreleri.

Tünel grubunda VSM çıkarma süresi $62 \pm 19 \mathrm{dk}$., insizyonu kapama süresi $9 \pm 3 \mathrm{dk}$. ve total süre $72 \pm 13 \mathrm{dk}$. olarak saptanmıştır.

Endoskopik grupta VSM çıkarma süresi $6 \pm 9$ dk., insizyonu kapama süresi $8 \pm 1 \mathrm{dk}$. ve total süre $70 \pm 10 \mathrm{dk}$. olarak saptanmıştır.
Üç grup birbiri ile karşılaştıııldığında VSM çıkarma süreleri klasik grup lehine anlamlı şekilde azalmış olarak saptanmıştır ( $P=0.012)$. VSM insizyonunu kapama süreleri de tünel ve endoskopik gruplar lehine anlamlı şekilde azalmış olarak saptanmıştır $(P=0.000)$. Total süre olarak anlamlı fark izlenmemiştir ( $P=0.883)$. Tünel ve endoskopik gruplar kendi içinde karşılaştıııldığında anlamlı fark bulunmamış$\operatorname{tir}(P=0.196)$.

\section{VSM uzunluğu özellikleri}

Ölçülen VSM uzunluğu; klasik grupta $54 \pm 13 \mathrm{~cm}$, tünel grubunda $47 \pm 12 \mathrm{~cm}$ ve endoskopik grupta ise $41 \pm 12 \mathrm{~cm}$ olarak saptanmıştır. Her üç grupta VSM uzunluğu açısından anlamlı fark saptanmamıştır ( $P=0.007)$.

\section{İnsizyon uzunluğu özellikleri}

Ölçülen insizyon uzunluğu; klasik grupta $54 \pm 13 \mathrm{~cm}$, tünel grubunda $19 \pm 6 \mathrm{~cm}$ endoskopik grupta ise $13 \pm 5 \mathrm{~cm}$ olarak saptanmıştır (Şekil 2). Her üç grupta ölçülen insizyon uzunluğu tünel ve endoskopik grup lehine anlamlı şekilde azalmış olarak saptanmıştır $(P=0.000)$.

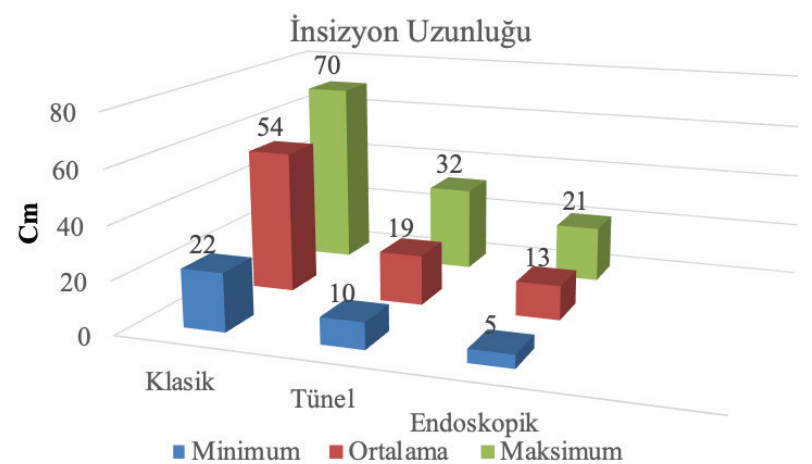

Şekil 2: Grupların insizyon uzunlukları. 
Tünel ve endoskopik grup arasında ölçülen insizyon uzunluğu açısından istatistiki olarak anlamlı fark saptanmamıştır $(P=0.593)$.

\section{Drenaj miktarı}

Tünel grubundaki olguların postoperatif ortalama drenaj miktarı $37 \pm 30 \mathrm{cc}(0-100 \mathrm{cc})$ ve endoskopik grupta ise $79 \pm 61$ cc $(0-200$ cc) olarak belirlenmiştir. Her iki grubun drenaj miktarları karşılaştııılığında anlamlı fark saptanmamıştır $(P=0.062)$.

\section{Postoperatif ağrı özellikleri}

Olguların VAS (Visual Analoque Scale) ile postoperatif 1, 3, 7. günde ve taburculuktan sonraki ilk kontrollerinde kaydedilen ağrı değerleri Şekil 3'te gösterilmiştir.

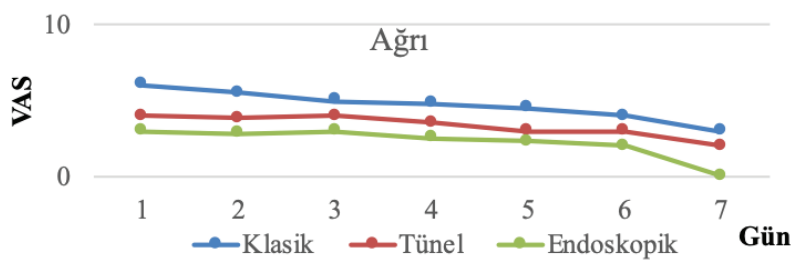

Şekil 3: Postoperatif ağı değerleri.

Ağrı düzeyi 1. günde, 3. günde, 7. günde ve taburculuktan sonraki ilk kontrollerinde sırasıyla klasik grupta, $6 \pm 1$, $4 \pm 0,3 \pm 0$ ve $2 \pm 0$; tünel grubunda $4 \pm 0,3 \pm 0,2 \pm 0$ ve $0 \pm 0$ ve endoskopik grupta ise 3:0, 2:0, 00 ve 0-0 olarak saptanmıştır. Her üç grup arasındaki ağrı değerlendirilmesi tünel ve endoskopik gruplar lehine anlamlı şekilde azalmış olarak bulunmuştur $(\mathrm{P}=0.000)$.

\section{Hastanede kalış süresi özellikleri}

Postoperatif hastanede kalış süresi klasik grupta $10 \pm 2$ gün, tünel grubunda $8 \pm 2$ ve endoskopik grupta ise $7 \pm 2$ gün olarak saptanmıştır. Bu sonuçlarla postop hastanede kalış süresi klasik ve tünel grubu arasında tünel grubu lehine azalmış olarak saptanmıştır $(P=0.003)$. Klasik ve endoskopik grubun karşılaştırı masında ise endoskopik grup lehine hastanede kalış süresinde azalma söz konusudur $(P=0.002)$.

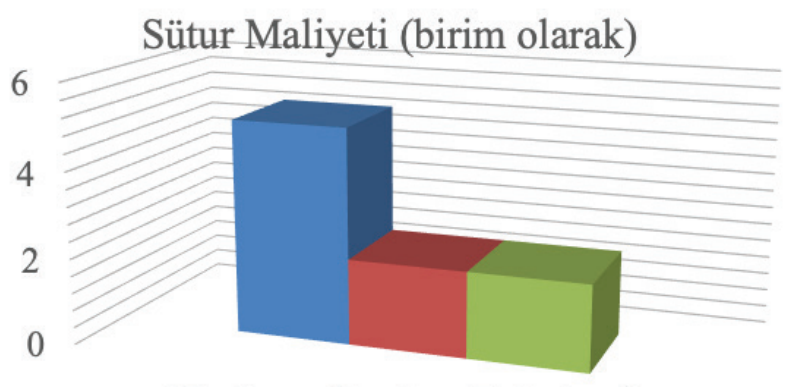

- Klasik -Tünel Endoskopik

Şekil 4: VSM insizyonun kapatılmasında kullanılan toplam sütur maliyeti.

\section{Maliyet}

Klasik grupta ortalama insizyonların kapatılmasında 5 birim materyal kullanılmıştır. Bu sayı tünel ve endoskopik grupta 2 birim olarak saptanmıştır. Bu birim içinde sütür ve haemovac $®$ dren maliyeti birim olarak belirlenmiştir (Şekil 4).

Bu sonuçla, insizyonları kapamada kullanılan materyalin maliyeti tünel ve endoskopik grubun lehine anlamlı şekilde azalmış olarak saptanmıştır $(\mathrm{P}=0.000)$.

\section{Üst bacak çapı}

Her üç grubun preoperatif femoral arter nabzının $10 \mathrm{~cm}$ aşağısından kaydedilen üst bacak çapları; klasik grupta $47.4 \mathrm{~cm}$, tünel grubunda $49.3 \mathrm{~cm}$ ve endoskopik yöntem grubunda $49.2 \mathrm{~cm}$ olarak kaydedildi. Bu sonuçla her üç grup arasında üst bacak çapı açısından anlamlı fark gözlenmedi $(P=0.181)$.

\section{Komplikasyon}

Gruplar arasında komplikasyon sayısı klasik grupta 3 hasta $(15 / 3=\% 20)$, tünel grubunda 2 hasta $(15 / 2=\% 13.3)$ ve endoskopik grupta ise 1 hasta (10/1=\%10) olarak belirlenmiştir (Şekil 5). Görülen komplikasyonların \%50'si klasik grupta, \%33.3'ü tünel grubunda ve \%16.7'si de endoskopik grupta saptanmıştır. Klasik yöntem grubunda gelişen 3 komplikasyonun özellikleri incelendiğinde; birinci hastada üst bacakta insizyonun üst ucunda $10 \mathrm{~cm}^{\prime}$ lik alanda postoperatif 4. günde açılma, ek cerrahi, ek antibiyotik tedavisi ve hastanede kalışı 4 gün uzatan bakım olmuştur. İkinci hastada üst bacakta medial bölgede cilt flebi altında diffüz hematom ile üzerindeki ciltte minimal nekroz gözlenmiş, pansuman bakımı gerekmiş ve hastanede kalışı 3 gün uzamıştır. Üçüncü hastada ise postoperatif 5. günde başlayan, 3 gün kadar süren ve günlük sık pansumanla kontrol edilen sızıntı olmuştur. Tünel grubunda komplikasyon gelişen hastaların özelliklerinde ise 1 hastada diz bölgesindeki insizyonda minimal hematom, 2. hastada ise postoperatif 4. gün başlayan ve 1 gün kadar süren üst bacak insizyonunda sızıntı olmuştur. Bu gruptaki hastalara ek cerrahi ve ek antibiyotik uygulanmamıştır ve hastanede kalışını uzatacak derecede sorunla karşılaşılmamıştır. En-

\section{Komplikasyonun gruplara göre \%'si}

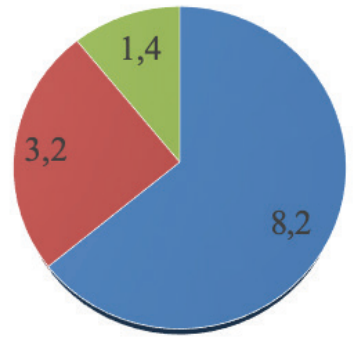

- Klasik - Tünel "Endoskopik

Şekil 5: Komplikasyonların gruplara göre \% dağılımı. 
doskopik yöntem grubunda ise sadece 1 hastada üst bacak insizyonunda postoperatif 3. günde olan ve ortalama 24 saat süren sızıntı bakım ile sonlandııımıştır. Ek cerrahi ve ek antibiyotik uygulanmamıştır ve hastanede kalışını uzatacak derecede sorunla karşılaşılmamıştır. Her üç grup kendi içerisinde karşılaştıııldığında komplikasyon gelişimi bakımından anlamlı fark gözlenmemiştir ( $P=0.069)$.

\section{İnsizyon uzunluğu/VSM uzunluğu oranı}

Insizyon uzunluğu/VSM uzunluğu oranı; klasik grupta $1.01 \pm 0.14$, tünel grubunda $0.40 \pm 0.09$ ve endoskopik grupta $0.34 \pm 0.15$ olarak saptanmıştır. Bu sonuçlar ile bir birim VSM çıkarmak için kullanılan insizyon uzunluğu tünel ve endoskopik grubunda klasik gruba oranla anlamlı şekilde azalmış olarak bulunmuştur ( $\mathrm{P}=0.000)$.

\section{VSM uzunluğu/çıkarma süresi}

VSM uzunluğu/çıkarılma süresi oranı; klasik grupta $1.29 \pm 0.74$, tünel grubunda $0.99 \pm 0.79$ ve endoskopik grupta $0.67 \pm 0.25$ olarak saptanmıştır. Bu sonuçlarla birim zamanda çıkarılan VSM uzunluğu karşılaştıııldığında klasik grup lehine anlamlı şekilde yüksek olarak bulunmuştur $(\mathrm{P}=0.000)$

\section{VSM uzunluğu/insizyonu kapama süresi}

VSM uzunluğu/insizyonu kapama süresi oranı; klasik grupta 2.28 \pm 0.78 , tünel · VSM grubunda $5.41 \pm 1.66$ ve endoskopik grupta $5.36 \pm 2.35$ olarak saptanmıştır. Elde edilen bir birim VSM uzunluğu için gerekli insizyonu kapama süresi tünel ve endoskopik grupta klasik gruba göre anlamlı azalmış bulunmuştur $(P=0.000)$.

\section{TARTISSMA}

Arteriyel greftlerin kullanılmasının giderek artmasına rağmen VSM koroner revaskülarizasyonda sıklıkla tercih edilmektedir $(6,11)$. VSM çıkarılması yüzeyel bir insizyonla yapılmasına karşın hastalarda önemli morbidite ve buna bağlı ağı ve memnuniyetsizliğe neden olmaktadır. VSM çıkarılan alanda gelişen komplikasyonlar nedeniyle oluşan postoperatif morbidite ve hasta rahatsızlığı kardiyak cerrahinin tüm başarısına gölge düşürebilmektedir (9). Bu çalışma ile koroner baypas cerrahisinin önemli bir unsuru olarak gördüğümüz VSM çıkarma yöntemlerini incelemeyi amaçladık.

Farklı yöntemlerle VSM çıkarırken yapılan insizyon uzunlukları, Allen ve arkadaşlarının yaptığı çalışma ile birlikte bir çok çalışmada karşılaştırılmış, endoskopik teknik ve tünel yöntemi ile VSM insizyon uzunluğunda klasik yönteme göre belirgin azalma olduğu saptanmıştır $(1,7,12)$. Bizim çalışmamızda VSM çıkarılırken uygulanan insizyonların uzunluğu karşılaştııılığında literatürle paralel olarak tünel ve endoskopik grupta klasik gruba oranla istatistiki olarak anlamlı azalma saptanmışıtı. Tünel ve endoskopik grup kendi aralarında karşılaştırıldığında ise aralarında anlamlı fark saptanmamıştır.
Yapılan çalışmalarda klasik yöntemle endoskopik ve tünel yönteminde elde edilen VSM uzunluğu karşılaştııılığında farklılığa rastlanmamıştır $(13,14)$. Bizim çalışmamızda da çıkarılan vena safena magna uzunlukları karşılaştııılığında gruplar arasında fark gözlenmemiştir. Tünel ve endoskopik yöntem grubunda, aynı uzunlukta VSM greftini çıkarmak için kullanılan insizyon uzunluğu azalmışır.

VSM çıkarma süresi açısından farklı yöntemler karşılaştırıldığında minimal invaziv yöntemlerde çıkarma sürelerinin daha uzun olduğu gözlenmiştir (13). Çıkarılma zamanı öğrenme süresince kısalmış olmasına rağmen, süre klasik yönteme göre daha uzun kalmıştır (13). Ancak, Davis ve arkadaşları, endoskopik yöntem ile klasik yöntemi karşılaştırdıkları çalışmada; endoskopik grupta insizyon kapama süresinin oldukça kısa olduğunu görmüşlerdir. Bu çalışmada, gruplar arasında VSM çıkarma süreleri karşılaştırıldığında bu sürenin tünel ve endoskopik grupta anlamlı olarak daha uzun olduğu gözlendi. Literatürle paralel olarak öğrenme süresince çıkarma süresi giderek azaldı. VSM çıkarılma süresi, endoskopik ve tünel grupları klasik yöntem grubu ile karşılaştırıldığında daha uzun olmasına karşın her üç grupta operasyon ve VSM çıkarılması ve insizyonun kapatılmasını içeren total sürede anlamlı bir fark gözlenmedi.

Folliguet ve arkadaşları sızıntı ve hematomdan kaçınmak için insizyonlara küçük drenaj sistemleri yerleştirmişlerdir. Drenaj miktarına göre bu sistemler 24-48 saat süre takip edilmiştir (1) Çalışmaya alınan tünel ve endoskopik grupta iki insizyon arasındaki tünelde olabilecek kanama ve lenfatik sızıntılar için drenaj sistemleri yerleştirildi. Yerleştirilen drenaj sistemindeki drenaj miktarlarında iki grup arasında anlamlı fark saptanmamıştır.

VSM çıkarılması nedeniyle gelişen, postoperatif anestezi, hipoestezi ve ağrı ile seyreden safenöz nöralji, genellikle safen sinirinin dağılım alanında olmaktadır. Safenöz sinir sensorial bir sinirdir ve klasik yöntemde ven çıkarılırken vene eşlik ettiği için genellikle kesilmekte ya da kapatılırken sütur ile yaralanmaktadır. Postoperatif safenöz nöralji semptomlarının ortaya çıkması klasik yöntemde artmaktadır (15). Minimal invaziv yöntemlerde ise diz bölgesinde travmanın azalması nedeni ile daha az ağrı olmakta, hasta rahatlığı ve erken mobilizasyonu sağlamakta, bununla birlikte postoperatif yaşam kalitesinin artığı saptanmıştır $(16,17)$.

Uygulanan farklı yöntemlerin maliyeti karşılaştııldığında, Allen ve arkadaşları endoskopik materyalin getirdiği ek maliyetin klasik yöntemdeki komplikasyonlar nedeniyle gereken ek bakım ve hastanede kalış süreleri tarafından telafi edildiği için iki grup arasında maliyet farkı gözlememiştir (2). Endoskopik kitin maliyetinin komplikasyonların tedavi masraflarından daha ucuza geldiği saptanmıştır (1, 2). Laringoskop Langenback retraktör, ışıklı retraktör ve Richardson retraktör gibi disposabl olmayan materyelle- 
rin kullanıldığı tünel yönteminde ek maliyet olmadığı için endoskopik yönteme göre maliyetin daha da avantajı olduğu bildirilmiştir $(7,18)$. Çalışma sırasında gruplarda VSM çıkarıması ve insizyonun kapatılmasında kullanılan cerrahi materyaller karşılaştııılığında endoskopik kitin ek maliyeti göz önünde tutulmadığı zaman tünel ve endoskopik gruplarda maliyetin anlamlı oranda azaldığı gözlenmiştir. Tünel grubunda kullanılan Langenback Retraktörün rutin cerrahi malzemeler içerisinde bulunması ve resteril edilerek kullanılabilir olması ek maliyeti gerektirmemektedir. Endoskopik grupta kullanılan Ethicon Endosurgery materyalinin de resteril edilerek kullanılabilir olması maliyetin azaltılmasını sağlamaktadır.

Koroner baypas sonrasında VSM çıkarılan bacakta izlenen en sık komplikasyonlar; sellülit, lenfanjit, ödem, inflamasyon ve yağ nekrozu olarak sayılabilir (5). Bir çok çalışmada, VSM çıkarılmasında tünel ve endoskopik yöntemler ile klasik yönteme göre major ve minor komplikasyonlarda belirgin azalma olduğu gözlenmiştir $(19,20)$.

Major yara yeri komplikasyonları VSM çıkarılan alanda belirgin bir morbidite yaratarak hastanede kalış süresini uzatır, masrafları artıır ve ek olarak deformite ve yürüme zorluklarına neden olabilmektedir (6). Leipzig'den Fabricius'un yaptığı araştırmada tünel ve endoskopik yöntemlerle yapılan VSM insizyon alanında \%20-40 arasında minor komplikasyon olan ekimoz, hematom ve inflamasyona rastlanmıştır. Buna karşın klasik teknikte \%60-65 arasında komplikasyon olarak lenfödem, dokuda ayrılma, lokal inflamasyon, nekroz ve ekimoz'a rastlanmıştır (21). Endoskopik grupta en sık görülen komplikasyon ekimoz olarak (\%12) saptanmıştır (22). Andreas Lehman ve arkadaşlarının Vaso view endoskopik çıkarma yöntemi kullanarak VSM çıkardıkları bir olguda bacaktaki subkutan dokuyu genişletmek için kullandıkları CO2'in kasıktaki büyük damarlar boyunca ilerleyerek retroperitona geçip pneumoperitoneuma neden olduğu bildirilmiştir (23). Minimal invaziv tekniklerde yara yeri komplikasyonlarının ciddiyeti açısından bakıldığında, önemli ölçüde azalma mevcuttur $(24,25)$.

Çalışmada klinik gözlem olarak ele alındığında klasik grupta daha yoğun bakım, ek cerrahi ve hastanede kalışı uzatan komplikasyonlar gelişir iken; tünel yöntemi ve endoskopik gruplarda daha ılımlı komplikasyonlar gelişmiştir. Çalışmaya alınan gruplarda belirtildiği gibi tünel ve endoskopik yöntem de klasik yönteme göre hastanede kaIışını uzatacak VSM insizyon problemi ile karşılaşılmamıştır. Minimal invaziv yöntemlerle cilt insizyonunun azalması ile birlikte tünel ve endoskopik gruplarda cilt flebi oluşma riskinin azaldığı, cilt altı dokuların hava ile temasının önlenerek enfeksiyon riskinin azaldığını düşünmekteyiz.

Çalışma sırasında incelenen parametreler dışında klinik olarak; tünel ve endoskopik yöntemlerin güvenle kullanılabileceğini, efektif bir yöntem olduğunu ve çıkarılması sırasında vene zarar vermediğini gözlemledik. Ayrıca bu tekniklerle azalmış major insizyonel problem, daha az komplikasyon, mükemmel bir kozmetik sonuç, daha kısa sürede iyileşme, uzamayan hastanede kalış süresi, daha az ağı nedeni ile hasta memnuniyeti yanında mobilizasyonun daha rahat ve erken dönemde olduğu gözlenmiştir. Tüm bu sonuçlar göz önüne alındığında, tünel tekniği ve endoskopik yöntemlerin klasik yönteme üstünlüğü göz önünde bulundurulmalıdır.

\section{KISITLAYICI FAKTÖRLER}

Komorbiditesi olan hastalar (diyabet, obezite) çalışmamızdan çıkarılmamıştır. Çalışmamızda kullanılan vaka sayısı sınırlı olup makalenin en önemli kısıtlayıcı faktörünü oluşturmaktadır.

Bilgilendirilmiş Onam: Katılımcılardan bilgilendirilmiş onam alınmıştır.

Hakem Değerlendirmesi: Dış bağımsız.

Yazar Katkıları: Çalışma Konsepti/Tasarım- I.E., D.M.Ö., M.M., M.U., Ö.O.; Veri Toplama- I.E., D.M.Ö., M.U.; Veri Analizi/Yorumlama- I.E., D.M.Ö., M.M., M.U.; Yazı Taslağı- I.E., D.M.Ö., M.M., M.U.; iç̧eriğin Eleştirel Incelemesi- I.E., D.M.Ö., M.M., M.U. Ö.O.; Son Onay ve Sorumluluk- I.E., D.M.Ö., M.M., M.U., Ö.O.

Çıkar Çatışması: Yazarlar çıkar çatışması beyan etmemişlerdir.

Finansal Destek: Yazarlar finansal destek beyan etmemişlerdir.

Informed Consent: Written consent was obtained from the participants.

Peer Review: Externally peer-reviewed.

Author Contributions: Conception/Design of Study- i.E., D.M.Ö., M.M., M.U., Ö.O.; Data Acquisition- I.E., D.M.Ö., M.U.; Data Analysis/Interpretation- I.E., D.M.Ö., M.M., M.U.; Drafting Manuscript- I.E., D.M.Ö., M.M., M.U.; Critical Revision of Manuscript- I.E., D.M.Ö., M.M., M.U., Ö.O.; Final Approval and Accountability- I.E., D.M.Ö., M.M., M.U., Ö.O.

Conflict of Interest: Authors declared no conflict of interest.

Financial Disclosure: Authors declared no financial support.

\section{KAYNAKLAR}

1. Folliguet TA, Le Bret E, Moneta A, Musumeci S, Laborde F. Endoscopic saphenous vein harvesting versus 'open' technique. A prospective study. Eur J of Cardiothorac Surg 1998;13:662-6. [CrossRef]

2. Isgro $F$, Weisse $U$, Voss B, Kiessling AH, Saggau W. Minimally invasive saphenous vein harvesting.is there an improvement of the results with the endoscopic approach? Eur J Cardiothorac Surg 1999;16(Suppl. 2):58-60. [CrossRef] 
3. Lutz CW, Schlensak C, Lutter G, Schöllhorn J, Beyersdorf F. Minimal-invasive, video assisted vein harvesting for cardiac and vascular surgical procedures. Eur J Cardiothorac Surg 1997;12:519-21. [CrossRef]

4. Hoenig SJ, Hodin RA, Novak G, Cohn WE. Videoscopic harvest of inferior epigastric artery. Ann Thorac Surg 1999;67:565-6. [CrossRef]

5. Utley JR, Thomason ME, Wallace DJ, Mutch DW, Staton L, Brown $V$, et al. Preoperative corralates of impaired wound healing after saphenos vein excision. J Thorac Cardivasc Surg 1989;98:147-9.

6. Paletta CE, Huang DB, Fiore AC, Swartz MT, Rilloraza FL, Gardner JE. Major leg wound complications after saphenous vein harvest for coronary revascularization. Ann Thorac Surg 2000;70:492-7. [CrossRef]

7. Slaughter MS, Gerchar DC, Pappas PS. Modified minimally invasive technique for greater saphenous vein harvesting. Ann Thorac Surg 1998;65:571-2. [CrossRef]

8. Cable DG, Dearani JA, Pfeifer EA, Daly RC, Schaff HV. Minimally invasive saphenous vein harvesting:Endotelial integrity and early clinical results. Ann Thorac Surg 1998;66:139-43. [CrossRef]

9. Coppoolse R, Rees W, Krech R, Hufnagel M, Seufert K, Warnecke $H$. Routine minimal invasive vein harvesting reduces postoperative morbidity in cardiac bypass procedures. Clinical report of 1400 patients. Eur J Cardiothorac Surg 1999;16(suppl 2):61-6. [CrossRef]

10. Kent KC, Bartek S, Kuntz KM, Anninos E, Skillman JJ. Prospective study of wound complications in continuous infrainguinal incisions after lower limb arterial reconstruction: incidence, risk factors, and cost. Surgery. 1996;119(4):378-83. [CrossRef]

11. El-Akkawi Al, Holdflod Møller CJ, Olsen PS, Carranza CL. Saphenous vein harvesting techniques for coronary artery bypass grafting. Ugeskr Laeger. 2019 Jan 14;181(3).

12. Li JY, Wang SS, Lin FY, Tsai CH, Chu SH. Video-assisted endoscopic saphenous vein harvesting for coronary artery baypass grafting. J Formos Med Assoc 1998;97(12):819-25.

13. Davis Z, Jacobs HK, Zhang M, Thomas C, Castellanos $Y$. Endoscopic vein harvest for coronary artery bypass grafting: technique and outcomes. J Thorac Cardivasc Surg 1998;116:228-35. [CrossRef]
14. Cusimano RJ, Dale L, Butany JW. Minimally invasive cardiac surgery for removal of the greater saphenous vein. Can J Surg 1996;39(5):386-8.

15. El Gamel A, Dyde J, Perks J, Shaw R. Should we stitch the subcutaneous fat layer following saphenous vein excision for coronary revascularization? Eur J Cardiothorac Surg 1994;8:162-4. [CrossRef]

16. Stavridis GT, Bobos D, Matsouka F, Lacoumenta S, Alivizatos PA. Minimally invasive long saphenous vein harvesting using a laryngoscope. Heart Surg Forum 1998;1(1):37-40.

17. Allen KB, Griffith $G L$, Heimansohn DA, Robison RJ, Matheny RG, Schier JJ, et al. Endoscopic versus traditional saphenous vein harvesting: a prospective, randomized trial. Ann Thorac Surg 1998;66:26-32. [CrossRef]

18. Newman RV, Lammle WG. Minimally invasive vein harvest :New techniques with Old Tools. Ann Thorac Surg 1999;67:571-2. [CrossRef]

19. Cusimano RJ, Dale L, Butany JW. Minimally invasive cardiac surgery for removal of the greater saphenous vein. Can J Surg 1996;39(5):386-8.

20. Lutz CW, Schlensak C, Lutter G, Schöllhorn J, Beyersdorf F. Minimal-invasive, video assisted vein harvesting for cardiac and vascular surgical procedures. Eur J Cardiothorac Surg 1997;12:519-21. [CrossRef]

21. Fabricius AM, Diegeler A, Doll N, Weidenbach $H$, Mohr FW. Minimally invasive saphenous vein harvesting techniques:morphology and postoperative outcome. Ann Thorac Surg 2000;70:473-8. [CrossRef]

22. Carrizo GJ, Livesay JJ, Luy L. Endoscopic harvesting of the greater saphenous vein for aortocoronary bypass grafting. Tex Heart Inst J 1999;26(2):120-3.

23. Johnson PR, Tan SL, Chin AK. Endoscopic femoralpopliteal/distal bypass grafting: a perliminary report. J Am Coll Surg 1998;186:331-6. [CrossRef]

24. Shiang SW, Vendargon SJ, Hamid SRBGS. Conventional versus Minimally Invasive Vein Harvesting: A Clinical Audit of Wound Dehiscence Complications. J Coll Physicians Surg Pak. 2019;29(4):371-4. [CrossRef]

25. Ma GT, Liu XR, Zhang CJ, Liu JZ, Miao Q, Jiang C, et al. Endoscopic Saphenous Vein Harvesting versus Open Vein Harvesting Techniques. Zhongguo Yi Xue Ke Xue Yuan Xue Bao. 2015;37(4):420-3. 